\title{
A laminar burning velocity and flame thickness correlation for ethanol-air mixtures valid at spark-ignition engine conditions
}

\author{
J. Vancoillie ${ }^{\mathrm{a}}$, J. Demuynck ${ }^{\mathrm{a}}$, J. Galle ${ }^{\mathrm{a}}$, S. Verhelst ${ }^{\mathrm{a}}$, J.A. van Oijen ${ }^{\mathrm{b}}$ \\ ${ }^{a}$ Department of Flow, Heat and Combustion Mechanics, Ghent University \\ Sint-Pietersnieuwstraat 41 B-9000 Gent, Belgium \\ ${ }^{\mathrm{b}}$ Department of Mechanical Engineering, Eindhoven University of Technology \\ 5600 MB Eindhoven, The Netherlands
}

\begin{abstract}
The use of biomass-derived ethanol in spark-ignition engines is an interesting option to decarbonize transport and increase energy security. An engine cycle code valid for this fuel, could help to explore its full potential. Crucial building blocks to model the combustion in ethanol engines are the laminar burning velocity and flame thickness of the ethanol-air-residuals mixture at instantaneous cylinder pressure and temperature.

15 This information is often implemented in engine codes using correlations. A literature survey showed that the few available flame thickness correlations have not yet been validated for ethanol. Also, none of the existing ethanol laminar burning velocity correlations covers the entire temperature, pressure and mixture composition range as encountered in spark-ignition engines. Moreover, most of these correlations are based on measurements that are compromised by the effects of flame stretch and the occurrence of flame instabilities. For this reason, we started working on new correlations based on flame simulations using a one-dimensional chemical kinetics code.

In this paper the published experimental data for the laminar burning velocity of ethanol are reviewed. Next, the performance of several reaction mechanisms for the 25 oxidation kinetics of ethanol-air mixtures is compared. The best performing mechanisms are used to calculate the laminar burning velocity and flame thickness of these mixtures in a wide range of temperatures, pressures and compositions. Finally, based on these calculations, correlations for the laminar burning velocity and flame thickness covering the entire operating range of ethanol-fuelled spark-ignition engines, are presented. These correlations can now be implemented in an engine code.
\end{abstract}

Keywords: ethanol, spark-ignition engine, thermodynamic, modelling, laminar burning velocity, laminar flame thickness, chemical kinetics

\section{Introduction}

Rising fuel prices, air pollution and the consequences of global warming make the need for a sustainable alternative for fossil fuels painfully clear. The use of biomass-

Preprorresminonding author Tiel:: +32(0)92643453; Fax: +32(0)92643590 
derived ethanol in spark-ignition engines is receiving increasing attention these days, since it is an interesting option to decarbonize transport and increase energy security. Compared to other promising alternatives, such as hydrogen and battery electric vehicles, liquid ethanol entails less issues regarding transport and distribution and is easily

40 stored in a vehicle. In addition, it can be blended with standard gasoline in variable amounts, facilitating a gradual transition to renewable fuels.

Bio-ethanol blends can be used in low-cost spark-ignition engines with only minor adjustments. Unlike many other alternative fuels, they have the potential to increase the engine performance and efficiency while reducing emissions compared to gasoline.

45 This is especially true for blends with high ethanol content (e.g. E85, E100). An interesting way to expedite evolution towards these high concentration blends is to use them in flexible fuel vehicles. These engines give the driver the choice what fuel to use, but their performance is usually a compromise between operation on gasoline or alcohol.

State-of-the-art flex-fuel vehicles utilize the evaporative cooling effect of alcohols 50 to suppress knock in highly charged engines with direct injection. Saab reports that such engines can attain $20 \%$ more power on E85, whereas the mean brake thermal efficiency over the New European Driving Cycle improves by over 5\% compared to operation on gasoline [1].

Alternatively, the favourable characteristics of ethanol can be fully exploited in ded-

55 icated engines. These engines produce high levels of power and efficiency through the use of design measures such as high compression ratios and downsizing, but this makes them unfit for operation on gasoline. To illustrate their potential, researchers at the U.S. Environmental Protection Agency converted a production 1.9 litre turbocharged diesel engine with a compression ratio of 19.5:1 to run on neat ethanol in SI mode and were ${ }_{60}$ able to attain peak effective thermal efficiencies higher than the baseline diesel engine (>40\%) [2]. EGR levels up to 50\%, made possible through the high dilution tolerance of ethanol, were used to spread the high efficiency regions to part-load operating points. These experimental results illustrate the potential of ethanol. A more comprehensive discussion on the favourable properties of alcohols and their use in spark-ignition engines can be found in [3, 4].

Despite these promising experimental results, the full potential of bio-ethanol in modern engine technology and its impact on possible control strategies remain to be explored. With current trends like elevated pressure-charging (downsizing), variable valve timing, exhaust gas recirculation, etc. it is no longer possible for an $R \& D$ ento gineer to intuitively grasp how these technologies and their combinations will affect the engine performance and pollutant emissions. Today however, these issues can be addressed at low cost using system simulations of the whole engines, provided that the employed models account for the effect of the fuel on the combustion process.

Predictive engine codes require a turbulent combustion model to track the progress 75 of the flame front through the cylinder. These combustion models generally assume fast chemistry (i.e. flamelet combustion regime). The influence of turbulence is then limited to flame stretching and the increase of flame front area, whereas the contribution of chemical reactions is grouped in the laminar burning velocity. This is a physicochemical property of the fuel-air-residuals mixture and thus a fundamental building so block of any engine model. Another important flame property is the laminar flame thickness $\delta_{l}$. Several recent turbulent combustion models use this property to estimate 
the ability of different turbulence scales to wrinkle the flame front and strain the flame $[5,6,7]$.This is done to reflect the observation that compared to thick flames, thin flames can be wrinkled by smaller turbulent length scales, thus producing more surface area and higher turbulent burning velocities.

Both laminar burning velocity and flame thickness are dependent on pressure, unburned mixture temperature and composition. Therefore turbulent combustion models require their values at instantaneous in-cylinder conditions. A convenient way to implement laminar burning velocity and flame thickness data in an engine cycle code

${ }_{90}$ is by using a correlation that gives their values in terms of pressure, temperature and composition of the unburned mixture. Unfortunately, none of the published laminar burning velocity correlations covers the entire range of conditions as encountered in ethanol-fuelled spark-ignition engines. Their validity is also doubtful, since most of them are based on outdated measurements which do not account for the effects of flame stretch and instabilities on the burning velocity. For flame thickness $\delta_{l}$ different fuelindependent correlations have been proposed, but these have not yet been validated for ethanol-air flames.

The present work seeks to evaluate the existing correlations for the laminar burning velocity and flame thickness of ethanol-air flames. It was completed within the framework of developing a multi-zone thermodynamic engine code valid for alcohol-fuelled engines. A first part of the paper reviews the published data on ethanol laminar burning velocity. We evaluated to what extent the current correlations cover the operating range of ethanol-fuelled engines and selected the most reliable experimental results. Besides reviewing experimental work, we also examined different reaction mechanisms for the oxidation kinetics of ethanol-air mixtures. A series of calculations were performed using the one dimensional chemical kinetics code CHEM1D [8] in order to determine which mechanisms could best represent the experimental values for the laminar burning velocity. Using these selected mechanisms, we calculated the burning velocity of ethanol-air mixtures under a broad range of mixture compositions, pressures and 10 temperatures. Finally, based on this set of calculations, the performance of existing laminar burning velocity and flame thickness correlations is evaluated and improved correlations are proposed.

\section{Choice of chemical kinetic scheme}

\subsection{Experimental determination and numerical calculation of laminar burning veloc- ity}

Most published laminar burning velocity correlations are based on a limited set of experimental data. Table 1 summarizes the major experimental investigations of ethanol laminar burning velocity. An in-depth review of the employed measurement methodologies and reliability of the results was published in [9]. The main conclusions are repeated here and some more recent experimental data and insights are added.

In [9] the in-cylinder conditions of future flex-fuel and dedicated ethanol engines are defined as in Table 2. When comparing this to the experimental domains in Table 1, it can be seen that the validation range of current correlations $[10,11]$ is rather limited. Data at elevated pressure is scarce and none of the investigations look at high levels of dilution. 
Moreover, most of the older $u_{l}$ data is compromised by the effects of flame stretch and instabilities. For example, Gülder [10], who published one of the earliest extensive measurement sets, investigated the flame propagation of contained explosions in a closed vessel. This is a popular way to measure $u_{l}$ at elevated pressures. The flame propagation can either be derived from pressure measurements in the vessel $[10,12]$ or directly captured by a high speed camera and a Schlieren optical system $[11,13,14,15,16]$. The stretch due to the curvature of these spherical flames can lead to substantial under or overestimations of the real burning velocities if not corrected for $[10,15]$. Additionally the spherical flames can develop instabilities such as

135 cellularity at high pressures and temperatures. These can cause overestimations of the true burning velocity at these conditions [10]. Gülder ignored these two effects in his research. Consequently his correlation can be expected to give incorrect $u_{l}$ values. In more recent publications, the effects of stretch and instabilities are accounted for. Still, the right method to correct for flame stretch remains subject to debate [17, 18].

As mentioned above, experimental determination of laminar burning velocities at engine-like conditions is hampered by the occurrence of flame instabilities and incorrect stretch corrections cause scatter amongst published data. Computationally, these effects can be avoided by assuming one-dimensional, planar adiabatic flames. The accuracy of burning velocities calculated with this assumption then depends on the cor-

145 rectness of the chemical kinetic reaction scheme and the precision of the rate constants and molecular transport coefficients. Understandably, the validation of reaction mechanisms against laminar burning velocities is very limited at best. Most mechanisms are therefore more widely validated. Typically they are tested on the basis of measured ignition delay times, flame extinction stretch rates, concentration profiles from flow reactors and flame data from burners. The accuracy of such a comprehensive mechanism is then a trade-off between the several applications it was developed for.

Several researchers have developed comprehensive mechanisms for the oxidation kinetics of ethanol-air mixtures (see Table 3). In order to determine which mechanisms are most fit to calculate laminar burning velocities under engine-like conditions, a num155 ber of simulations were run with a one-dimensional chemical kinetics code (CHEM1D) [8]. This code was developed at Eindhoven University of Technology and employs the EGLIB complex transport model [19], including multicomponent transport and thermal diffusion. In each case the solution was calculated using the exponential differencing technique in a grid consisting of 200 points, with most of the detail centred at the inner flame layer. Radiation was neglected and solver convergence confirmed by ensuring that all residuals were below $10^{-10}$ and the laminar burning velocity had reached a stable value. A grid independence test was performed to eliminate the large trunctation errors from inadequate grid resolution. It was shown that the laminar burning velocity differed by less than $1 \%$ between 200 and 400 grid points.

\subsection{Comparison of experimental and numerical results}

\subsubsection{Laminar burning velocity at varying equivalence ratio}

The predictive performance of various ethanol oxidation mechanisms is tested for premixed flames at $358 \mathrm{~K}, 1$ bar and for varying equivalence ratio in Figure 1. The mechanisms of Marinov [20], Li et al. [21], Saxena and Williams [22] and Konnov et 
al. [23] are included in the comparison. These are some of the more recent and widely validated ethanol mechanisms available [9]. Röhl and Peters [24] have published a reduced version of the Marinov mechanism that gives almost identical results to the original scheme (not shown here).

The experimental datasets of Bradley et al. [14], Konnov et al. [25] and Egol-

175 fopoulos et al. [26] are chosen as point of reference. Bradley et al. [14] performed the most extensive contemporary experimental investigation of ethanol-air burning velocity. They captured the flame growth of contained explosions using a high speed camera and a Schlieren optical system. A linear extrapolation to zero stretch was performed after removing all cellular flames and flames over-driven by spark energy from

${ }_{180}$ the dataset. Konnov et al. [25] used an interesting alternative set-up to measure the laminar burning velocity of ethanol-air mixtures at atmospheric pressure. They used a flat flame burner to stabilize non-stretched flames on a perforated plate burner. The so-called heat flux method was used to determine the burning velocity under conditions where the net heat loss from the flame to the burner is zero. The overall accuracy on the measured burning velocities was estimated to be better than $1 \mathrm{~cm} / \mathrm{s}$. Note the strong correspondence between these two recent datasets, although the authors gathered their data using completely different measurement methods. Van Lipzig et al. [27] partly repeated the measurement set of Konnov et al. [25] using an identical setup. Their experimental values were systematically higher, which was traced back to an incorrect 190 placing of the outer thermocouple on the perforated plate burner in the work of Konnov et al. The difference in maximum burning velocity was about $2 \mathrm{~cm} / \mathrm{s}$ and for lean flames the divergence mounted to 3-4 cm/s. Egolfopoulos et al. [26] employed a counterflow twin-flame burner to measure the burning velocity of ethanol for a range of equivalence ratios (0.5-2) at atmospheric pressure and modest temperatures (363-453 K). Because the typical strain rate in their flames is quite small (about $100 \mathrm{~s}^{-1}$ ), they used a linear extrapolation to zero stretch, which was later reported to lead to overestimations of the true burning velocity of up to $10 \%$ [18]. On Figure 1 it can be seen that the $u_{l}$ values of Egolfopoulos et al. are consistently higher than the other datasets, especially around stoichiometry.

Also plotted in Figure 1 are the expressions of Liao et al. [11] and Eisazadeh-Far et al. [12] to demonstrate the predictive capabilities of current laminar burning velocity correlations. Liao et al. [11] founded their correlation on measurements gathered using a similar method as Bradley et al. Eisazadeh-Far et al. also employed contained explosions, but derived the burning velocity using pressure measurements and a multi205 zone burning model. Only stable flames with radii higher than $4 \mathrm{~cm}$ (corresponding to stretch rates less than $70 \mathrm{~s}^{-1}$ ) were retained in their dataset to exclude the effects of flame stretch and instabilities. This restricted the usable data to equivalence ratios between 0.8 and 1.1, temperatures between 300 and $650 \mathrm{~K}$ and pressures below 5 bar. Both correlations predict burning velocities comparable to the values of Bradley et 210 al. and Konnov et al. for equivalence ratios below 1.1. For rich mixtures the correlation of Liao et al. gives slightly lower values.

When comparing the calculation results using the chemical kinetic mechanisms to the experimental burning velocity values, it can be seen that for lean to stoichiometric mixtures all schemes predict higher burning velocities than the values reported by 215 Konnov et al. and Bradley et al. Keeping in mind the observations of Van Lipzig et 
al. [27] one can expect the results of Konnov et al. to be $2-4 \mathrm{~cm} / \mathrm{s}$ too low. For slightly rich mixtures the mechanism of Marinov gives the best match with the data of Konnov et al. and Bradley et al. For very rich mixtures there is not much to choose between the four mechanisms under consideration.

220 2.2.2. Laminar burning velocity at varying unburned mixture temperature

Figure 2 shows the laminar burning velocities for a range of unburned mixture temperatures and for stoichiometric mixtures at atmospheric pressure. Compared to Figure 1 the individual data points of Liao et al. [11] and the correlation of Marshall et al.[28] are added. Similar to Eisazadeh-Far et al., Marshall et al. derived the burning velocity using pressure measurements and a multi-zone burning model. Cellular flames were removed from the dataset after visual inspection of Schlieren photographs of the flame front. The readings will thus be influenced by the criteria used to define the onset of cellularity. No stretch correction was applied, but the authors claim that the mean error due to stretch should be around $2 \mathrm{~cm} / \mathrm{s}$. However, it is difficult to estimate to what extent measurements at low and high temperatures are equally affected. From Figure 2 it can be seen that for low to intermediate temperatures the difference between the mechanisms remains negligible. For temperatures exceeding $500 \mathrm{~K}$ the mechanism of Marinov predicts significantly lower values (10\%) than the other mechanisms. Looking at the correlations of Liao et al. and Eisazadeh-Far et al. the temperature evolution 235 predicted by the Marinov scheme seems more trustworthy. However, the data points gathered by Liao et al. and the correlation of Marshall et al. support the steeper temperature gradient. Actually, the temperature range of the available measurement data is too restricted and the uncertainty on measurements too large to draw any sound conclusion on the temperature behaviour of the various mechanisms.

\subsubsection{Laminar burning velocity at varying pressure}

The dataset of Ohara et al. [15] and especially that of Bradley et al. [14] provide interesting information on the pressure behaviour of ethanol-air flames. Figure 3 compares the calculated $u_{l}$ against these datasets for varying pressure at $353 \mathrm{~K}$ and for three different equivalence ratios. Also included are the correlations of Liao et al. [11] and

245 Eisazadeh et al. [12], and the dataset of Varea et al. [29] at $\phi=1$ and $T_{u}=373 \mathrm{~K}$. Similarly to Bradley et al., Varea et al. obtained the burning velocity by capturing the flame growth during contained explosions.

The dataset of Ohara et al., Bradley et al. and Varea et al. suggest an exponential decrease in burning velocity with increasing pressure. For this reason the results from the chemical kinetic calculations are displayed on a logarithmic coordinate system. It is clear that the current correlations underpredict the drop in burning velocity with increasing pressure. The pressure dependence of the correlation of Liao et al. is based on measurements of Gülder et al. [10], which possibly overestimate the true burning velocity of high pressure flames due to the inclusion of cellular flames. Eisazadeh et

255 al. excluded cellular flames from their dataset, but this left them with a dataset that was very limited in pressure range $(<4$ bar at $\phi=1)$.

For lean to stoichiometric mixtures, all mechanisms predict a similar pressure decrease as measured by Bradley et al., Ohara et al. and Varea et al. Note that the results of Varea et al. are measured at $373 \mathrm{~K}$ and therefore somewhat higher. As mentioned 


\section{Laminar burning velocity correlation}

\subsection{Evaluation of published correlations}

Based on the calculated flame database of over 1500 conditions, the existing laminar burning velocity and flame thickness correlations of ethanol-air mixtures can be

300 evaluated. As shown in Table 1 only a few laminar burning velocity correlations for ethanol-air mixtures were published. All of these use the form shown in Equation 1 to 
express the influence of equivalence ratio, pressure, unburned mixture temperature and residual gas content on the burning velocity. This form has frequently been used for various fuels.

$$
u_{l}=u_{l 0} \cdot\left(T_{u} / T_{u 0}\right)^{\alpha} \cdot\left(p / p_{0}\right)^{\beta} \cdot(1-\gamma f)
$$
Verhelst et al. for the laminar burning velocity of hydrogen-air mixtures [30]. 


\subsection{New laminar burning velocity correlation}

340 For reasons mentioned above, the functional form proposed by Verhelst et al. was selected for the correlation (Eq. 2). To make the pressure and temperature non-dimensional the standard reference conditions were used ( $p_{0}=1 \mathrm{bar}, T_{0}=300 \mathrm{~K}$ ).

For undiluted mixtures the exponent $\alpha$ and coefficient $u_{l 0}$ of the power relation were determined at each combination of $\phi$ and $p$. However, inspection of the dataset for ethanol-air mixtures revealed that the proposed power relation only holds for temperatures below $900 \mathrm{~K}$. For temperatures above $900 \mathrm{~K}$ and at elevated pressures, there were substantial deviations. This behaviour is due to the fact that at these temperatures the mixture self-ignites and the definition of laminar burning velocity has no physical sense (the self-ignition temperature of ethanol is $698 \mathrm{~K}$ at atmospheric conditions).

350 Consequently, the calculation results at the highest pressures ( $>85$ bar) and temperatures $(\geq 900 \mathrm{~K})$ were removed from our dataset.

The Levenberg-Marquardt algorithm [31] was used to fit the calculated $\alpha$ and $u_{l 0}$ values as a function of $\phi$ and $p$. This algorithm seeks to reduce the sum of the squared differences (SSD) between the observed and predicted values. Due to the large spread in $u_{l}$ values (ranging from a few $\mathrm{cm} / \mathrm{s}$ to more than $2 \mathrm{~m} / \mathrm{s}$ ) a weighting parameter was used during the fitting, to ensure an accurate fit also for the lower burning velocities. The weighting was set to the squared reciprocal of the observed value as this gave the best results. Each of the proposed equations (see below, Eqs. 3-4) in this paper is the result of a large number of iterations, whereby different functional forms were fitted to the data. Initially these forms consisted of only linear terms in the different variables $\left(p / p_{0}, \phi, f, T / T_{0}\right)$. Progressively terms were added, first pure quadratic terms $\left(\left(p / p_{0}\right)^{2}, \phi^{2}, f^{2},\left(T / T_{0}\right)^{2}\right)$ followed by linear cross terms (e.g. $\left(p / p_{0}\right) \cdot\left(T / T_{0}\right)$, $\left.\left(T / T_{0}\right) \cdot f, \ldots\right)$, inverse linear terms (e.g. $\left.1 /\left(p / p_{0}\right)\right)$ and progressively higher order terms and combinations of these factors. This was continued until the resulting SSD no 365 longer decreased. Once this stage was reached it was attempted to trim the equation, by selectively removing terms one by one to see their impact on the SSD. The resulting fit was always visually compared to the original simulation data to confirm the effect of each parameter was well represented by the correlation form.

Table 4 lists the coefficients to determine $\alpha(\phi, p)$ using Eq. 3 and $\ln \left[u_{l 0}(\phi, p)\right]$ using Eq. 4. Due to the large variation in $u_{l 0}$ values it was decided to fit $\ln u_{l 0}$ in order to reduce the complexity of the fit. Note that Eq. 4 is third order in $p$, whereas the burning velocity decreases exponentially with increasing pressure. This leads to underestimated burning velocities at the lowest pressures $(<10 \mathrm{bar})$. These points are not that important considering the intended purpose of the correlations in an engine simulation code.

$$
\begin{aligned}
\alpha(\phi, p)=a_{1}+a_{2} \phi+ & a_{3} \frac{p}{p_{0}}+a_{4} \phi \frac{p}{p_{0}}+ \\
& a_{5} \phi^{2}+a_{6}\left(\frac{p}{p_{0}}\right)^{2}+a_{7} \phi^{3}+a_{8}\left(\frac{p}{p_{0}}\right)^{3}+ \\
& a_{9} \phi^{2} \frac{p}{p_{0}}+a_{10} \phi^{2}\left(\frac{p}{p_{0}}\right)^{2}+\frac{a_{11}}{\phi}+\frac{a_{12}}{\phi} \frac{p}{p_{0}}
\end{aligned}
$$




$$
\begin{aligned}
& \ln \left[u_{l 0}\right](\phi, p)=b_{1}+b_{2} \phi+b_{3} \frac{p}{p_{0}}+b_{4} \phi \frac{p}{p_{0}}+ \\
& b_{5} \phi^{2}+b_{6}\left(\frac{p}{p_{0}}\right)^{2}+b_{7} \phi^{3}+b_{8}\left(\frac{p}{p_{0}}\right)^{3}+ \\
& b_{9} \phi^{2} \frac{p}{p_{0}}+b_{10} \phi^{2}\left(\frac{p}{p_{0}}\right)+\frac{b_{11}}{\phi}
\end{aligned}
$$

Once the correlation for undiluted mixtures is known, an expression for residual gas correction term can be constructed. As mentioned above, the best way to capture the influences and interactions of $\phi, p, T_{u}$ and $f$ on the correction term $F$, is by fitting this term as a complicated polynomial function. The data series for the correction term is computed as the ratio of the calculated dataset values, with residuals, to the corresponding values without residuals, predicted using the correlation proposed above (Eqs. 2-4, F=1). Using a similar procedure as described above a functional form was determined for the correction term, minimizing the SSD. During this fitting procedure the smallest $u_{l}$ values $(<1 \mathrm{~cm} / \mathrm{s})$ were removed from the dataset. The lowest burning velocities occur for extreme equivalence ratios $(0.5,2.0)$ at the highest concentrations of residual gases (>30 vol\%). These flames might exist computationally, but are not considered appropriate for engine simulations. Table 5 lists the coefficients to determine $F_{1}\left(\phi, p, T_{u}, f\right)$ using Eq. 5. The correction term $F\left(\phi, p, T_{u}, f\right)$ is then found by limiting $F_{1}\left(\phi, p, T_{u}, f\right)$ to be smaller than or equal to 1 .

$$
\begin{gathered}
F_{1}\left(\phi, T_{u}, p, f\right)=c_{1}+c_{2} \phi+c_{3} \frac{T_{u}}{T_{0}}+c_{4} \frac{p}{p_{0}}+ \\
c_{5} f+c_{6} \phi^{2}+c_{7}\left(\frac{T_{u}}{T_{0}}\right)^{2}+c_{8} f^{2}+ \\
c_{9} \phi\left(\frac{T_{u}}{T_{0}}\right)+c_{10} \phi\left(\frac{p}{p_{0}}\right)+c_{11} \phi f+c_{12}\left(\frac{T_{u}}{T_{0}}\right) f+ \\
c_{13} \phi^{3}+c_{14} f^{3}+c_{15}\left(\frac{T_{u}}{T_{0}}\right) \phi^{2}+c_{16}\left(\frac{p}{p_{0}}\right) \phi^{2}+ \\
c_{17} \phi\left(\frac{T_{u}}{T_{0}}\right)^{2}+c_{18} f\left(\frac{T_{u}}{T_{0}}\right)^{2}+c_{19} \phi f^{2}+c_{20}\left(\frac{T_{u}}{T_{0}}\right) f^{2} \\
F\left(\phi, T_{u}, p, f\right)=\min \left[1, F_{1}\left(\phi, T_{u}, p, f\right)\right]
\end{gathered}
$$

The quality of the fit was checked by comparing the predicted $u_{l}$ values against the fitted data points and a batch of test data. This batch consisted of calculated $u_{l}$ data that were discarded in the fitting process at various equivalence ratios, pressures and unburned mixture temperatures. Table 6 provides an overview of the quality of the fit for ethanol-air mixtures, listing the average relative residual (Eq. 7), average absolute relative residual (Eq. 8), minimum and maximum residual and the percentage of data points that are predicted to within $\pm 10 \%$ and $\pm 20 \%$. As can be seen the relationship 
captures $93 \%$ of the fitted data to within $\pm 20 \%$ and has a mean absolute relative residual of $7.38 \%$. For the test data it has a mean absolute relative residual of $8.58 \%$ and captures $88.77 \%$ to within $\pm 20 \%$.

$$
\begin{gathered}
\text { average relative residual }=\frac{1}{N} \sum\left(\frac{u_{l, \text { pred }}-u_{l}}{u_{l}}\right) \\
\text { average absolute relative residual }=\frac{1}{N} \sum\left(\frac{\left|u_{l, \text { pred }}-u_{l}\right|}{u_{l}}\right)
\end{gathered}
$$

It is important to note that the largest differences occur for extreme values of $\phi(0.5$, 2.0), $p$ ( $\leq 5$ bar, $\geq 85$ bar) which is a result of the polynomial form of the equations. Additionally, the calculations showed aberrant behaviour at the highest temperatures $(\geq 800 \mathrm{~K})$ due to self-ignition. This led to a more than exponential rise of $u_{l}$ in terms of unburned mixture temperature and burning velocities that increased with rising diluent fraction. These results were not retained to fit the equations, but were included in this quality check.

Having determined the coefficients for the correction term $F$, the full correlation is now known. It consists of Eq. 2 whereby $\alpha(\phi, p), u_{l 0}(\phi, p)$ and $F\left(\phi, T_{u}, p, f\right)$ are computed through Eqs. 3-4-5-6 respectively, making use of the coefficients listed in Table 4 and Table $5, p_{0}$ and $T_{0}$ as given above, $f$ the volume fraction of residuals and $u_{l}$ given in $\mathrm{cm} / \mathrm{s}$. A $\mathrm{C}++$ implementation of the correlation is available online as supplementary material with this paper.

\section{Flame thickness correlation}

\subsection{Evaluation of published correlations}

Flame thickness influences the combustion process through its defining effect on flame-turbulence interaction. Thicker flames are less sensitive to small eddies and will therefore experience lower degrees of turbulence induced flame wrinkling. Some recent turbulent combustion models incorporate the effects of flame thickness, requiring an accurate knowledge of this quantity at engine-relevant conditions. For example, Bougrine et al. [32] used an efficiency function $\Gamma\left(u^{\prime} / u_{l}, l_{t} / \delta_{l}\right)$ proposed by Charlette et al. [6], which measures the ability of the different turbulent scales to wrinkle the flame front. Where $u^{\prime}$ is the intensity of velocity fluctuations, $l_{t}$ is the turbulence integral length scale and $\delta_{l}$ is the laminar flame thickness.

The model was derived by Charlette et al. from DNS of interactions between single vortices and a flame in order to measure the effective strain-rate of vortices of different characteristic sizes and speeds. Based on these DNS results they fitted an effective flame wrinkling function $\Gamma$ that accounts for all scales relevant to engine combustion. This efficiency function evaluates the surface-producing flame stretch across different combustion regimes. Obviously the influence of flame thickness is most pronounced for the thickened wrinkled flames regime $(\mathrm{Ka}>1)$ and the thickened flame regime $(\mathrm{Da}<1)$. In these regimes, the thickness of the flame limits the smallest turbulence scales in wrinkling the flame front. In the wrinkled flame regime the assumption 
of infinitely thin flamelets is more valid and the influence of flame thickness is negligible.

To limit computational efforts in engine simulations, this laminar flame thickness $\delta_{l}$ is also determined using a correlation. For conventional hydrocarbon fuels different flame thickness correlations have been proposed in the literature. The Zel'dovich correlation expresses the flame thickness in terms of the laminar flame speed and the fresh gases properties [33]:

$$
\delta_{l}^{\text {Zeldovich }}=\left(\frac{\lambda}{\rho \cdot C_{p}}\right)_{u} \frac{1}{u_{l}}
$$

Where $\lambda$ is the thermal conductivity, $\rho$ the density and $C_{p}$ the heat capacity of the fresh gases. Another correlation was proposed by Blint [33] including a correction for burned gases properties using a Sutherland law for $\lambda$ and a constant Prandtl number of 0.7 :

$$
\delta_{l}^{\mathrm{Blint}}=2 \cdot\left(\frac{\lambda}{\rho \cdot C_{p}}\right)_{u} \frac{1}{u_{l}} \cdot\left(\frac{T_{b}}{T_{u}}\right)^{0.7}
$$

Where $T_{b}$ is the burned gases temperature. We compared these correlations against our database of calculated flames, where the flame thickness was estimated from the temperature gradients between the fresh and burned gases zones:

$$
\delta_{l}^{\mathrm{CHEM} 1 \mathrm{D}}=\frac{T_{b}-T_{u}}{\max (d T / d x)}
$$

Several flame thickness definitions have been proposed in the literature including definitions based on the temperature gradients, characteristic chemical time and the heat release rate. Blint states that a flame width definition based on temperature gradient is the most rational selection to provide an unambiguous specification of the laminar scale, since it can be directly determined from the temperature profile and incorporates both transport and heat release [33]. Still, this definition is not optimal as it implicitly assumes that temperature profiles have the same shape for all conditions, which might not necessarily be the case, especially around flammability limits [32].

Figure 6 compares the flame thickness calculated using the mechanism of $\mathrm{Li}$ et al. [21] against the correlations of Zel'dovich and Blint for varying equivalence ratio and at several pressures $\left(T_{u}=700 \mathrm{~K}, f=0 \mathrm{~mol} \%\right)$. In Figure 7 the correlations are compared against calculation results for varing diluent ratio and at different unburned mixture temperatures ( $p=15$ bar). Also included in the figures is a new correlation, which is discussed in section 4.2. The Zel'dovich correlation underestimates the cal460 culated flame thicknesses at all conditions. Blint's correlation shows better agreement, but errors increase for lean and rich mixtures at low pressures and highly diluted mixtures at low temperatures. In these conditions the largest overestimations of calculated flame thicknesses can be seen, both in absolute values as in percentual differences.

The same behaviour was noted by Bougrine et al. when they compared calculated flame thickness for methane-air flames against the correlations of Zel'dovich and Blint [32]. Bougrine et al. finally retained the correlation of Blint in their modelling work, because it predicts the right trends for flame thickness with pressure, unburned mixture 
temperature and equivalence ratios. Moreover the largest errors are seen in conditions that are of lower importance to engine modelling work and where the validity of the flame thickness definition based on temperature gradients is questionable. In this study, however, it was noted that the use of Blint's correlation led to an average overestimation of the calculated laminar flame thickness of over 13\%. Also, it was observed that in less then $31 \%$ of the calculated cases, the flame thickness was predicted within $10 \%$ (see Table 7). For this reason we attempted to make slight adjustments to Blint's correlation 475 in order to improve its predictive performance.

\subsection{New laminar flame thickness correlation}

A database of over 1500 calculated flames in the range of 1-85 bar for pressure, $400-900 \mathrm{~K}$ for the fresh gas temperature, $0.5-2$ for $\phi$ and diluent ratios up to $50 \mathrm{vol} \%$ was used to evaluate the Blint correlation for ethanol-air mixtures (see Table 7). The same database can now be used to fit an improved flame thickness correlation.

Knop [34] adapted Blint's correlation to hydrogen combustion by adding a multiplying factor $\kappa$. This factor $\kappa$ is unity for conventional hydrocarbons and depends on the equivalence ratio $\phi$, fresh gas temperature $T_{u}$ and the pressure $p$ for hydrogen:

$$
\kappa=\alpha \cdot f(\phi) \cdot g\left(T_{u}\right) \cdot h(p)
$$

Where $\alpha=3.37$ and $f, g$ and $h$ are second order polynomial functions of $\phi, T_{u}$ and $p$ respectively. In engine-like conditions $\kappa$ ranged from 2 to 7, which means that for the same laminar burning velocity the hydrogen flame is clearly thicker than the hydrocarbon counterpart.

For ethanol-air flames the errors associated with the Blint correlation were limited to $30 \%$ at over $80 \%$ of the calculated conditions (see Table 7). Consequently, it was preferred to keep the form of the correlation (Eq. 10), add a multiplying constant $\kappa$ and change the exponents for $u_{l}$ (from -1 to $\beta$ ) and $T_{b} / T_{u}$ (from 0.7 to 0.5 ).

The Sutherland law for $\lambda$ in its original form employs an exponent of 0.5 , so this value was used instead of 0.7 for the correction for burned gases properties:

$$
\lambda_{b}=\left(\frac{T_{b}}{T_{u}}\right)^{0.5} \cdot \lambda_{u}
$$

The proposed correlation for laminar flame thickness of ethanol-air mixtures is given by Eq. 14:

$$
\delta_{l}^{\mathrm{New}}=\kappa \cdot\left(\frac{\lambda}{\rho \cdot C_{p}}\right)_{u} \cdot u_{l}^{\beta} \cdot\left(\frac{T_{b}}{T_{u}}\right)^{0.5}
$$

Where $\kappa$ and $\beta$ are constants that were determined by minimizing the SSD between the flame thicknesses in our flame database and values predicted by the correlation. Two sets of constants were computed (see Table 8). The first set was fitted using the laminar burning velocity values calculated by CHEM1D as an input for the correlation. The second set employed the correlation proposed in the first part of this paper to predict $u_{l}$. Note that $u_{l}$ is expressed in $\mathrm{cm} / \mathrm{s}$, while the correlation gives $\delta_{l}$ in $\mathrm{cm}$. The predictive performance of Eq. 14 using both sets of values for $\kappa$ and $\beta$ is summarized in 
Table 8. A first thing to notice is that both sets are almost identical, which confirms the predictive performance of our laminar burning velocity correlation. The correlation using the CHEM1D results predicts the calculated flame thickness to within $10 \%$ in $78 \%$ of the observed conditions. In almost all conditions the errors on $\delta_{l}$ are below $20 \%$. The good fit with calculation results can also be observed in Figures 6 and 7 ('New' correlation). The largest deviations occur in conditions that are on the edge of self-ignition (high pressures and temperatures) or flame extinction (very rich or lean, 510 high amounts of residual gases). In these conditions the results of the chemical kinetic calculations and the definition of flame thickness based on temperature gradients are questionable.

The flame thickness correlation using our own correlation for burning velocity performs somewhat worse with only $70 \%$ of the calculated flame thickness being predicted to within $10 \%$. This is caused by an underprediction of the laminar burning velocity at low pressures $(\leq 5 \mathrm{bar})$. This results in an overestimation of the associated flame thickness. These low pressure conditions, however, are of minor importance for engine simulation purposes.

\section{Conclusions}

Bio-ethanol is an interesting alternative fuel for use in spark-ignition engines. The use of an engine cycle code valid for this light alcohol, could help to explore its full potential. Important building blocks for most predictive engine codes are the laminar burning velocity and flame thickness of the fuel-air-residuals mixture at instantaneous pressure and temperature. These parameters are conveniently implemented in engine

525 codes by using correlations that give their values in terms of pressure, temperature and composition of the unburned mixture.

In the first section of this paper, it was shown that for ethanol there is a lack of burning velocity correlations suitable for use in engine codes. In fact experimental laminar burning velocity data at engine-like conditions is very scarce, especially data 530 at elevated pressures and for diluted mixtures. Moreover, most of the published data and correlations are compromised by the effects of flame stretch and the occurrence of flame instabilities.

Computationally, these effects can be avoided by calculating one-dimensional, planar adiabatic flames using chemical oxidation mechanisms. A number of contemporary 535 chemical mechanisms for the oxidation kinetics of ethanol were selected from literature. The results from calculations with these mechanisms were compared against reliable experimental data for the laminar burning velocity for a range of pressures, temperatures, equivalence ratios and diluent ratios. Based on these studies the mechanism of $\mathrm{Li}$ et al. [21] was retained to calculate laminar flames for a wide range of 540 engine-like equivalence ratios (0.5-2), pressures (5-85 bar), unburned mixture temperatures $(400-900 \mathrm{~K})$ and diluents fractions $(0-50 \mathrm{vol} \%)$. It was noted that at temperatures above $900 \mathrm{~K}$ the mixture self-ignited, which renders the calculation results useless.

Using this database of computed flames, we constructed new correlations for the laminar burning velocity and flame thickness of ethanol-air mixtures. For the laminar burning velocity, it was shown that existing correlation forms cannot capture the 
strong interaction effects between equivalence ratio, pressure, temperature and diluent fraction. Therefore, a new correlation form was proposed:

$$
u_{l}\left(\phi, p, T_{u}, f\right)=u_{l 0}(\phi, p)\left(\frac{T_{u}}{T_{0}}\right)^{\alpha(\phi, p)} F\left(\phi, p, T_{u}, f\right)
$$

Where $\alpha(\phi, p), u_{l 0}(\phi, p)$ are third order polynomial functions of $\phi$ and $\mathrm{p}$ with various cross terms. The influence of residuals on the burning velocity is incorporated in a

550 and diluent fraction $f$. The proposed correlation form closely fits the detailed chemical kinetics results.

An evaluation of different flame thickness correlations demonstrated that the correlation of Blint predicts the right trends for $\delta_{l}$ of ethanol in terms of $\phi, T_{u}, p$ and diluent match our calculation results. Flame thicknesses were estimated from the temperature gradients in the computed flames.

The developed correlations can now be implemented in an engine cycle code. Future work will focus on further validating the correlations by comparing them to our engine experiments.

\section{Acknowledgements}

J. Vancoillie gratefully acknowledges a Ph. D. fellowship (FWO09/ASP/030) of the Research Foundation - Flanders.

\section{References}

[1] K. Bergström, H. Nordin, A. Konigstein, C. D. Marriot, M. A. Wiles, Abc - alcohol based combustion engines - challenges and opportunities, in: 16th Aachener Kolloquium Fahrzeug- und Motorentechnik, Aachen, 2007, pp. 1031-1072.

[2] M. J. Brusstar, M. Stuhldreher, D. Swain, W. M. Pidgeon, High efficiency and low emissions from a port-injected engine with neat alcohol fuels, SAE paper no. 2002-01-2743 (2002).

[3] R. Pearson, J. Turner, M. Eisaman, K. Littau, Extending the supply of alcohol fuels for energy security and carbon reduction, SAE paper no. 2009-01-2764 (2009).

[4] J. Vancoillie, S. Verhelst, Modeling the combustion of light alcohols in SI engines: a preliminary study, in: FISITA 2010 World Automotive Congress, Budapest, Hungary, 2010, pp. 1-12.

[5] S. Richard, S. Bougrine, G. Font, F.-A. Lafossas, F. L. Berr, On the reduction of a 3D CFD combustion model to build a physical OD model for simulating heat release, knock and pollutants in SI engines, Oil and Gas Science and Technology - Rev. IFP 64 (3) (2009) 223-242. 
[6] F. Charlette, C. Meneveau, D. Veynante, A power-law flame wrinkling model for les of premixed turbulent combustion. part i: Non-dynamic formulation and initial tests, Combustion and Flame 131 (1-2) (2002) 159-180.

[17] Z. Chen, On the extraction of laminar flame speed and markstein length from outwardly propagating spherical flames, Combustion and Flame 158 (2) (2011) 291-300. model across combustion regimes, Combustion Science and Technology 182 (3) (2010) $284-308$.

[8] Combustion Technology group, Technical University of Eindhoven. CHEM1D [online] (1994) [cited May 20th 2010].

URL http://w3.wtb.tue.nl/en/research/research_groups/ combustion_technology/research/flamecodes/chem1d/

[9] J. Vancoillie, S. Verhelst, J. Demuynck, Laminar burning velocity correlations for methanol-air and ethanol-air mixtures valid at SI engine conditions, SAE paper no. 2011-01-0846 (2011).

[10] O. L. Gülder, Burning velocities of ethanol isooctane blends, Combustion and Flame 56 (3) (1984) 261-268.

[11] S. Y. Liao, D. M. Jiang, Z. H. Huang, K. Zeng, Q. Cheng, Determination of the laminar burning velocities for mixtures of ethanol and air at elevated temperatures, Applied Thermal Engineering 27 (2-3) (2007) 374-380.

[12] K. Eisazadeh-Far, A. Moghaddas, J. Al-Mulki, H. Metghalchi, Laminar burning speeds of ethanol/air/diluent mixtures, Proceedings of the Combustion Institute 33 (2011) 1021-1027.

[13] T. Kimitoshi, H. Takashi, S. Fumio, Study of combustion properties of ethanol air mixtures, in: FISITA 2006 World Automotive Congress, Yokohama, Japan, 2006, pp. 1-10.

[14] D. Bradley, M. Lawes, M. S. Mansour, Explosion bomb measurements of ethanolair laminar gaseous flame characteristics at pressures up to 1.4 MPa, Combustion and Flame 156 (7) (2009) 1462-1470.

[15] K. Ohara, M. Tsukikawa, Y. Araki, A. Hayakawa, S. Kobayashi, T. Kitagawa, Jsme, Properties Of Ethanol Laminar And Turbulent Premixed Flames, Proceedings of the International Conference on Power Engineering 2009, Japan Soc Mechanical Engineers, Tokyo, 2009.

[16] J. Beeckmann, O. R'ohl, N. Peters, Experimental and numerical investigation of iso-octane, methanol and ethanol regarding laminar burning velocity at elevated pressure and temperature, SAE paper no. 2009-01-1774 (2009).

7] H. Kolla, J. W. Rogerson, N. Swaminathan, Validation of a turbulent flame speed 
[18] P. S. Veloo, Y. L. Wang, F. N. Egolfopoulos, C. K. Westbrook, A comparative experimental and computational study of methanol, ethanol and n-butanol flames, Combustion and Flame 157 (10) (2010) 1989-2004.

[19] A. Ern, V. Giovangigli. EGLIB: A multicomponent transport software for fast and accurate evaluation algorithms [online] (2004) [cited December 10th 2010]. URL http: //www . cmap.polytechnique.fr/www .eglib/home.html

[20] N. M. Marinov, A detailed chemical kinetic model for high temperature ethanol oxidation, International Journal of Chemical Kinetics 31 (3) (1999) 183-220.

[21] J. Li, A. Kazakov, M. Chaos, F. Dryer, Chemical kinetics of ethanol oxidation, in: 5th US Combustion Meeting, San Diego, US, 2007, pp. 1-17.

[22] P. Saxena, F. A. Williams, Numerical and experimental studies of ethanol flames, Proceedings of the Combustion Institute 31 (2007) 1149-1156.

[23] A. A. Konnov, Implementation of the ncn pathway of prompt-no formation in the detailed reaction mechanism, Combustion and Flame 156 (11) (2009) 2093-2105.

[24] O. Röhl, N. Peters, A reduced mechanism for ethanol oxidation, in: European Combustion Meeting, Wien, 2009, pp. 1-5.

[25] A. A. Konnov, R. J. Meuwissen, L. P. H. de Goey, The temperature dependence of the laminar burning velocity of ethanol flames, Proceedings of the Combustion Institute 33 (1) (2011) 1011-1019.

[26] F. N. Egolfopoulos, D. X. Du, C. K. Law, A study on ethanol oxidation kinetics in laminar premixed flames, flow reactors, and shock tubes, Symposium (International) on Combustion 24 (1) (1992) 833-841.

[27] J. P. J. van Lipzig, E. J. K. Nilsson, L. P. H. de Goey, A. A. Konnov, Laminar burning velocities of n-heptane, iso-octane, ethanol and their binary and tertiary mixtures, Fuel 90 (8) (2011) 2773-2781.

[28] S. P. Marshall, S. Taylor, C. R. Stone, T. J. Davies, R. F. Cracknell, Laminar burning velocity measurements of liquid fuels at elevated pressures and temperatures with combustion residuals, Combustion and Flame 158 (10) (2011) 1920-1932.

[29] E. Varea, V. Modica, A. Vandel, B. Renou, Measurement of laminar burning velocity and markstein length relative to fresh gases using a new postprocessing procedure: Application to laminar spherical flames for methane, ethanol and isooctane/air mixtures, Combustion and Flame 159 (2) (2011) 577-590.

[30] S. Verhelst, C. T'Joen, J. Vancoillie, J. Demuynck, A correlation for the laminar burning velocity for use in hydrogen spark ignition engine simulation, International Journal of Hydrogen Energy 36 (1) (2010) 957-974.

[31] J. More, The levenberg-marquardt algorithm: implementation and theory, in: The 1977 Dundee conference on numerical analysis, Lecture notes in mathematics 630, Springer Verlag, Berlin, Heidelberg, New York, Tokyo, 1978, pp. 105-116. 
[32] S. Bougrine, S. Richard, D. Veynante, On the combination of complex chemistry with a 0 -d coherent flame model to account for the fuel properties in spark ignition engines simulations: Application to methane-air-diluents mixtures, Proceedings of the Combustion Institute 33 (2) (2010) 3123-3130.

[33] R. J. Blint, The relationship of the laminar flame width to flame speed, Combustion Science and Technology 49 (1) (1986) 79 - 92.

[34] V. Knop, A. Benkenida, S. Jay, O. Colin, Modelling of combustion and nitrogen oxide formation in hydrogen-fuelled internal combustion engines within a $3 \mathrm{~d} \mathrm{cfd}$ code, International Journal of Hydrogen Energy 33 (19) (2008) 5083-5097.

[35] G. Broustail, P. Seers, F. Halter, G. Moreac, C. Mounaim-Rousselle, Experimental determination of laminar burning velocity for butanol and ethanol iso-octane blends, Fuel 90 (1) (2010) 1-6. 
Table 1: Overview of the ethanol-air burning velocity measurements in literature. * Correlation published. There is a lack of data at elevated pressures and for diluted mixtures.

\begin{tabular}{|c|c|c|c|c|c|c|c|}
\hline Year & Author & Ref. & Technique & $\mathrm{p}$ [bar] & $\mathrm{T}[\mathrm{K}]$ & $\phi$ & $\mathrm{f}[\mathrm{m} \%]$ \\
\hline 1982 & Gülder* & [10] & $\begin{array}{l}\text { Closed vessel, } \\
\text { flame ionization }\end{array}$ & $1-8$ & $298-800$ & $0.7-1.4$ & 0 \\
\hline 1992 & Egolfopoulos et al. & [26] & Counterflow & 1 & $363-453$ & $0.55-1.8$ & 0 \\
\hline 2006 & Liao et al.* & [11] & $\begin{array}{l}\text { Closed vessel } \\
\text { Schlieren }\end{array}$ & 1 & $385-480$ & $0.8-1.2$ & 0 \\
\hline 2006 & Kimitoshi et al. & [13] & $\begin{array}{l}\text { Closed vessel } \\
\text { Schlieren }\end{array}$ & 1 & 325 & $0.8-1.4$ & 0 \\
\hline 2009 & Bradley et al. & [14] & $\begin{array}{l}\text { Closed vessel } \\
\text { Schlieren }\end{array}$ & $1-14$ & $300-393$ & $0.7-1.5$ & 0 \\
\hline 2009 & Ohara et al. & [15] & $\begin{array}{l}\text { Closed vessel } \\
\text { Schlieren }\end{array}$ & $1-5$ & 298 & $0.8-1.4$ & 0 \\
\hline 2009 & Beeckmann et al. & [16] & $\begin{array}{l}\text { Closed vessel } \\
\text { Schlieren }\end{array}$ & 10 & 373 & $0.8-1.2$ & 0 \\
\hline 2010 & Veloo et al. & [18] & Counterflow & 1 & 343 & $0.7-1.5$ & 0 \\
\hline 2010 & Konnov et al. & [25] & $\begin{array}{l}\text { Flat flame } \\
\text { heat-flux method }\end{array}$ & & $298-358$ & $0.65-1.55$ & 0 \\
\hline 2011 & $\begin{array}{l}\text { Eisazadeh-Far et al.* } \\
\text { (Far) }\end{array}$ & [12] & $\begin{array}{l}\text { Closed vessel } \\
\text { Pressure derived }\end{array}$ & $1-5$ & $300-650$ & $0.8-1.1$ & $0-10$ \\
\hline 2011 & Broustail et al. & [35] & $\begin{array}{l}\text { Closed vessel } \\
\text { Schlieren }\end{array}$ & 1 & 393 & $0.8-1.4$ & 0 \\
\hline 2011 & Varea et al. & [29] & $\begin{array}{l}\text { Closed vessel } \\
\text { Schlieren }\end{array}$ & $1-5$ & 373 & $0.8-1.5$ & 0 \\
\hline 2011 & Marshall et al. & [28] & $\begin{array}{l}\text { Closed vessel } \\
\text { Pressure derived }\end{array}$ & $0.5-4$ & $400-650$ & $0.7-1.4$ & $0-30$ \\
\hline
\end{tabular}

Table 2: In-cylinder conditions in alcohol-fuelled engines

\begin{tabular}{c|c|c|c|c} 
engine type & $\mathrm{p}[\mathrm{bar}]$ & $\mathrm{T}[\mathrm{K}]$ & $\phi$ & EGR [m\%] \\
\hline flex-fuel & $1-100$ & $300-1000$ & $0-2.5$ & $0-20$ \\
dedicated & $1-150$ & $300-1500$ & $0-2.5$ & $0-50$
\end{tabular}


Table 3: Overview of the employed ethanol oxidation mechanisms and their validation range

\begin{tabular}{|c|c|c|c|c|c|c|c|c|}
\hline Year & Author & Ref. & Species & Reactions & Validation & $\mathrm{p}$ [bar] & $\overline{\mathrm{T}[\mathrm{K}]}$ & $\phi$ \\
\hline 1998 & $\begin{array}{l}\text { Marinov } \\
\text { (Mar.) }\end{array}$ & [20] & 57 & 383 & $\begin{array}{l}u_{l} \\
\text { shock tube } \\
\text { flow reactor }\end{array}$ & $1-4.5$ & $300-1700$ & $0.5-2.0$ \\
\hline 2006 & Li et al. & [21] & 39 & 238 & $\begin{array}{l}u_{l} \\
\text { shock tube } \\
\text { flow reactor }\end{array}$ & $1-13$ & $300-950$ & $0.3-1.4$ \\
\hline 2007 & $\begin{array}{l}\text { Saxena \& } \\
\text { Williams (S\&W) }\end{array}$ & [22] & 57 & 288 & $\begin{array}{l}u_{l} \\
\text { shock tube } \\
\text { flame struct. }\end{array}$ & $<100$ & $>1000$ & $<3$ \\
\hline 2009 & $\begin{array}{l}\text { Röhl \& } \\
\text { Peters }\end{array}$ & [24] & 38 & 228 & $\begin{array}{l}u_{l} \\
\text { flow reactor }\end{array}$ & $1-40$ & $300-800$ & $0.5-2$ \\
\hline 2009 & Konnov & [23] & 127 & 1200 & $u_{l}$ & 1 & 298-358 & $0.5-2$ \\
\hline
\end{tabular}

Table 4: Coefficients for Eq. 3 and 4

\begin{tabular}{lll}
$\mathrm{i}$ & $a_{i}$ & $b_{i}$ \\
\hline 1 & $3.717600 \mathrm{E}+00$ & $-3.123300 \mathrm{E}+00$ \\
2 & $-9.398400 \mathrm{E}+00$ & $2.054070 \mathrm{E}+01$ \\
3 & $3.980000 \mathrm{E}-02$ & $-5.880000 \mathrm{E}-02$ \\
4 & $-1.860000 \mathrm{E}-02$ & $9.329600 \mathrm{E}-03$ \\
5 & $8.413800 \mathrm{E}+00$ & $-1.617230 \mathrm{E}+01$ \\
6 & $-2.832200 \mathrm{E}-04$ & $7.285600 \mathrm{E}-04$ \\
7 & $-2.055000 \mathrm{E}+00$ & $3.633400 \mathrm{E}+00$ \\
8 & $1.401100 \mathrm{E}-06$ & $-3.097700 \mathrm{E}-06$ \\
9 & $-8.349800 \mathrm{E}-04$ & $4.372200 \mathrm{E}-03$ \\
10 & $4.319800 \mathrm{E}-05$ & $-1.179500 \mathrm{E}-04$ \\
11 & $1.332500 \mathrm{E}+00$ & $-1.434600 \mathrm{E}+00$ \\
12 & $-6.523800 \mathrm{E}-03$ & - \\
\hline
\end{tabular}


Table 5: Coefficients for Eq. 5

\begin{tabular}{cl|cl}
$\mathrm{i}$ & $c_{i}$ & $\mathrm{i}$ & $c_{i}$ \\
\hline 1 & $1.087600 \mathrm{E}+00$ & 11 & $5.054000 \mathrm{E}-01$ \\
2 & $1.088600 \mathrm{E}+00$ & 12 & $1.851200 \mathrm{E}+00$ \\
3 & $-4.133000 \mathrm{E}-01$ & 13 & $1.803000 \mathrm{E}-01$ \\
4 & $-2.787700 \mathrm{E}-03$ & 14 & $-2.108700 \mathrm{E}+00$ \\
5 & $-6.703000 \mathrm{E}+00$ & 15 & $1.680000 \mathrm{E}-02$ \\
6 & $-7.413000 \mathrm{E}-01$ & 16 & $-5.028100 \mathrm{E}-04$ \\
7 & $1.250000 \mathrm{E}-01$ & 17 & $4.040000 \mathrm{E}-02$ \\
8 & $8.049200 \mathrm{E}+00$ & 18 & $-2.813000 \mathrm{E}-01$ \\
9 & $-2.486000 \mathrm{E}-01$ & 19 & $-7.175000 \mathrm{E}-01$ \\
10 & $3.037800 \mathrm{E}-03$ & 20 & $-1.323600 \mathrm{E}+00$ \\
\hline
\end{tabular}

Table 6: Fitting statistics for Eq. 2 (full fit, $f \geq 0$ vol\%)

\begin{tabular}{lll} 
& $\begin{array}{l}u_{l, p r e d} \\
\text { fitted data }\end{array}$ & $\begin{array}{l}u_{l, p r e d} \\
\text { test data }\end{array}$ \\
\hline Average rel. residual & $0.61 \%$ & $-2.74 \%$ \\
Average abs. rel .residual & $7.38 \%$ & $8.58 \%$ \\
Maximum residual & $69.72 \%$ & $40.43 \%$ \\
Minimum residual & $-81.41 \%$ & $-60.82 \%$ \\
Data within $\pm 10 \%$ & $73.64 \%$ & $67.95 \%$ \\
Data within $\pm 20 \%$ & $93.30 \%$ & $88.77 \%$ \\
\hline
\end{tabular}

Table 7: Comparison of $\delta_{l}$ predicted by Blint's correlation (Eq. 10) against calculation results using the ethanol oxidation mechanism of Li et al. [21]

\begin{tabular}{ll} 
& $\delta_{l}^{\text {Blint }}$ \\
\hline Average rel. residual & $13.45 \%$ \\
Average abs. rel .residual & $17.27 \%$ \\
Maximum residual & $46.23 \%$ \\
Minimum residual & $-81.76 \%$ \\
Data within $\pm 10 \%$ & $30.88 \%$ \\
Data within $\pm 20 \%$ & $59.16 \%$ \\
Data within $\pm 30 \%$ & $81.52 \%$ \\
\hline
\end{tabular}


Table 8: Comparison of $\delta_{l}[\mathrm{~cm}]$ predicted by the adapted Blint correlation (Eq. 10) against calculation results. The left column summarizes the quality of the fit using calculated $u_{l}[\mathrm{~cm} / \mathrm{s}]$ values $\left(u_{l}^{\mathrm{CHEM} 1 \mathrm{D}}\right)$, the right column for the fit using $u_{l}[\mathrm{~cm} / \mathrm{s}]$ values predicted by Eq. 2-6 (u $\left.u_{l}^{\text {corr. }}\right)$

\begin{tabular}{lll} 
& $\delta_{l}\left(u_{l}^{\text {CHEM1D }}\right)$ & $\delta_{l}\left(u_{l}^{\text {corr. }}\right)$ \\
\hline$\kappa$ & 0.9505 & 0.9484 \\
$\beta$ & -0.9346 & -0.9382 \\
Average rel. residual & $1.12 \%$ & $0.75 \%$ \\
Average abs. rel .residual & $6.63 \%$ & $8.48 \%$ \\
Maximum residual & $25.70 \%$ & $52.71 \%$ \\
Minimum residual & $-81.68 \%$ & $-56.49 \%$ \\
Data within $\pm 10 \%$ & $78.43 \%$ & $70.65 \%$ \\
Data within $\pm 20 \%$ & $96.07 \%$ & $91.30 \%$ \\
Data within $\pm 30 \%$ & $98.75 \%$ & $96.00 \%$ \\
\hline
\end{tabular}

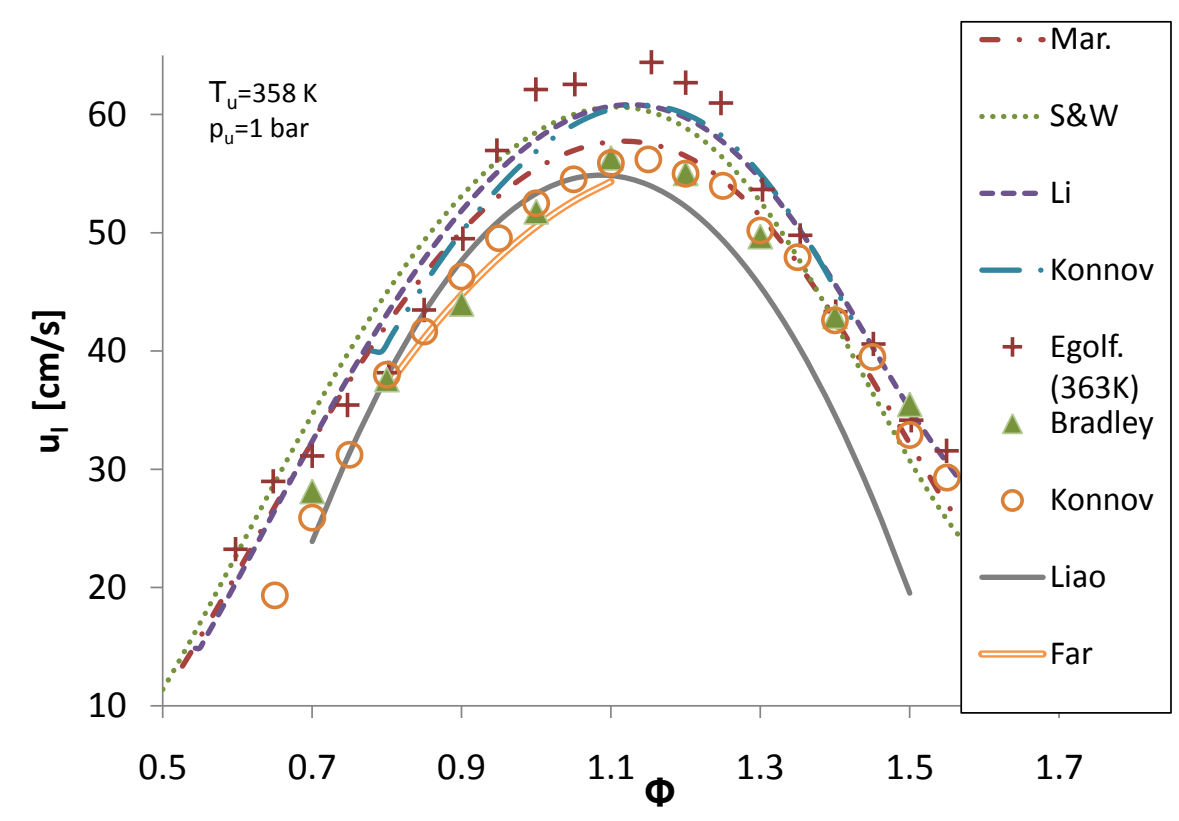

Figure 1: $u_{l}$ of ethanol-air as a function of $\phi\left(\mathrm{p}=1\right.$ bar, $\left.T_{u}=358 \mathrm{~K}\right)$. Comparison of chemical kinetic mechanisms (discontinuous lines), experimental data (markers) and existing correlations (full lines). References in Table 1 and 3 


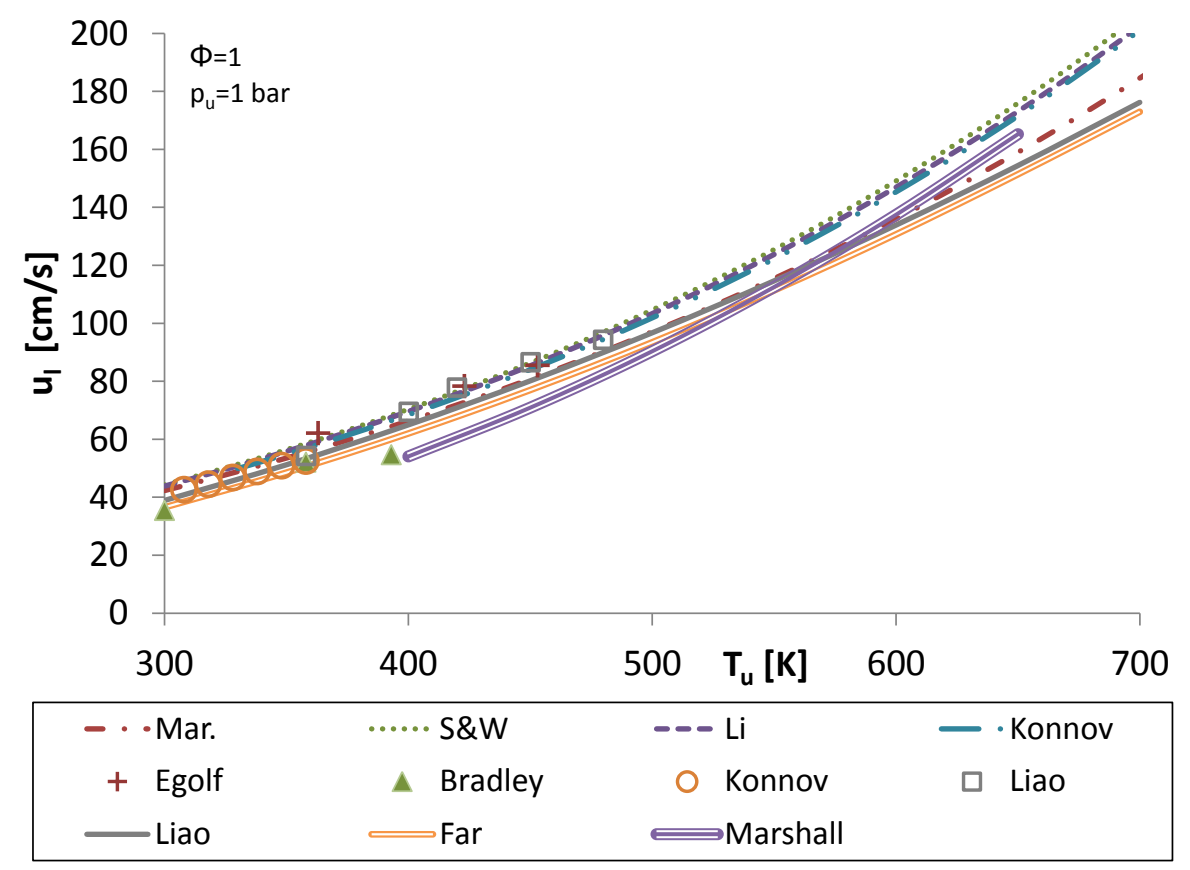

Figure 2: $u_{l}$ of ethanol-air as a function of $T_{u}(\mathrm{p}=1$ bar, $\phi=1)$. References in Table 1 and 3 


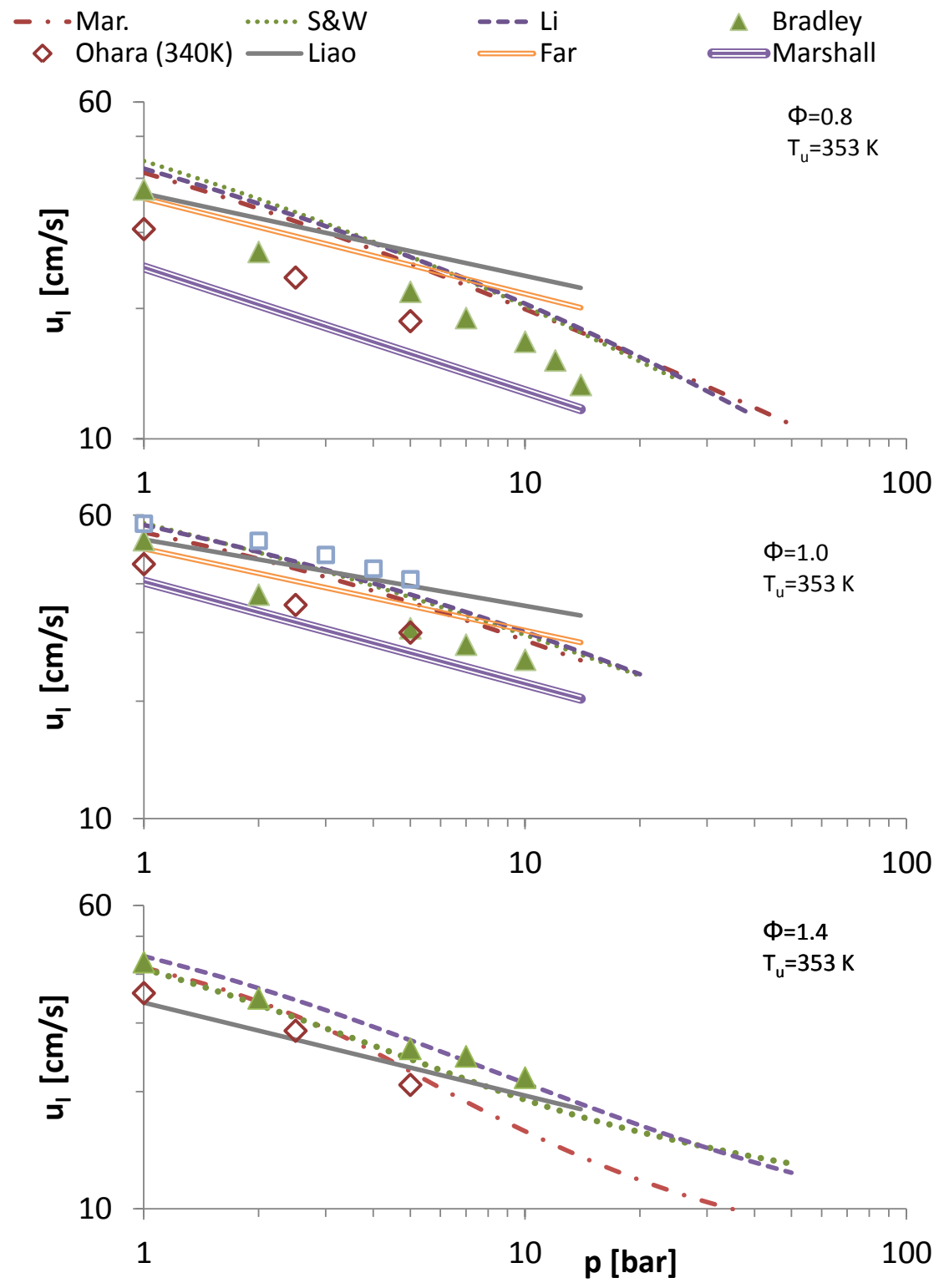

Figure 3: $u_{l}$ of ethanol-air as a function of $p$ at different equivalence ratios $\left(T_{u}=353 \mathrm{~K}\right)$. References in Table 1 and 3 


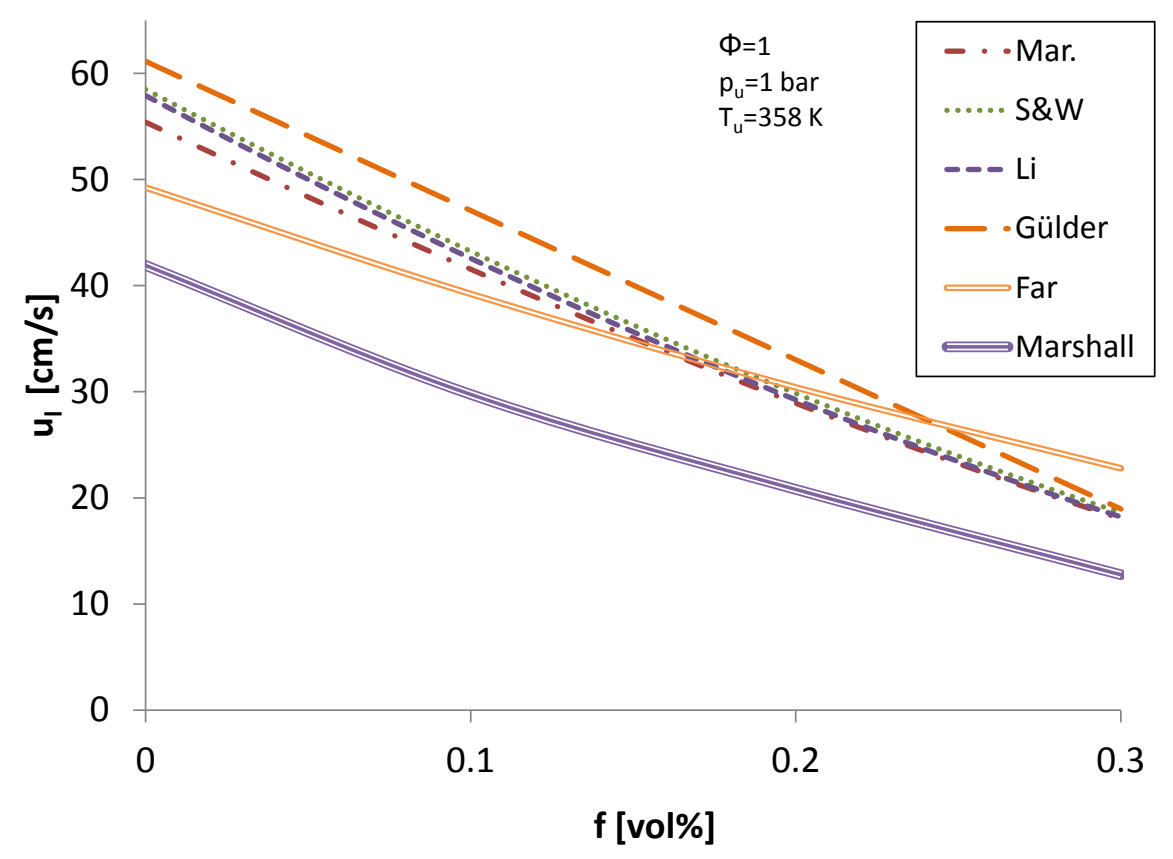

Figure 4: $u_{l}$ of ethanol-air as a function of $f\left(\mathrm{p}=1\right.$ bar, $\left.T_{u}=358 \mathrm{~K}, \phi=1\right)$. References in Table 1 and 3 


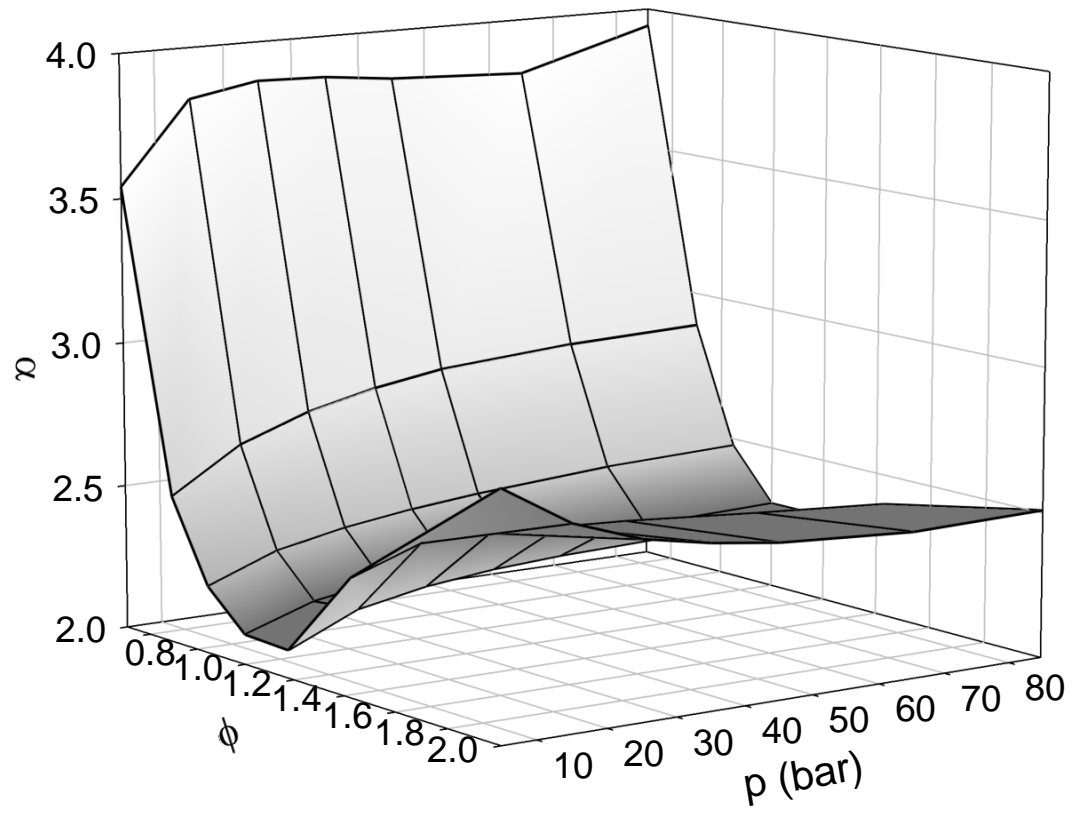

Figure 5: Calculated temperature exponent $\alpha$ of ethanol-air mixtures for a range of pressures and equivalence ratios. The calculated pressure behaviour of lean flames and rich flames is different. 


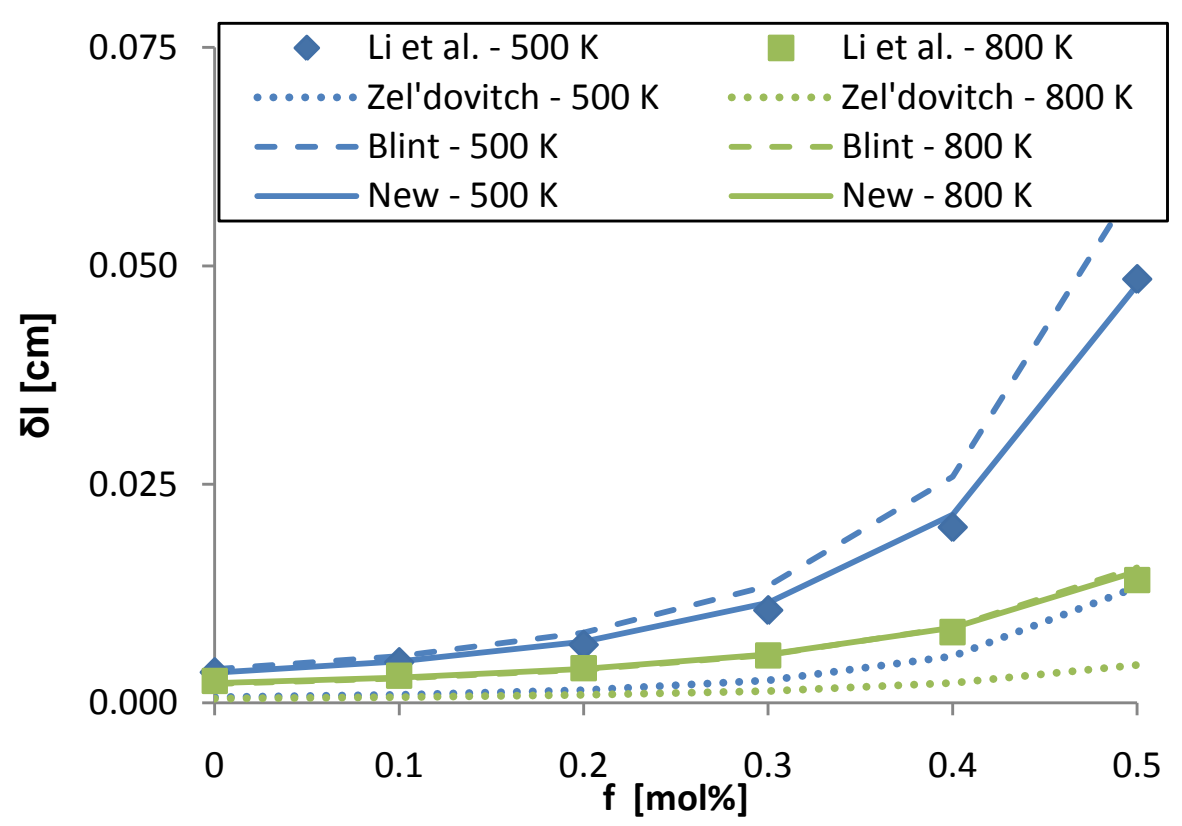

Figure 6: Laminar flame thickness variations with the equivalence ratio $\phi$ at different pressures $\left(T_{u}=700 \mathrm{~K}, f=0 \mathrm{~mol} \%\right)$

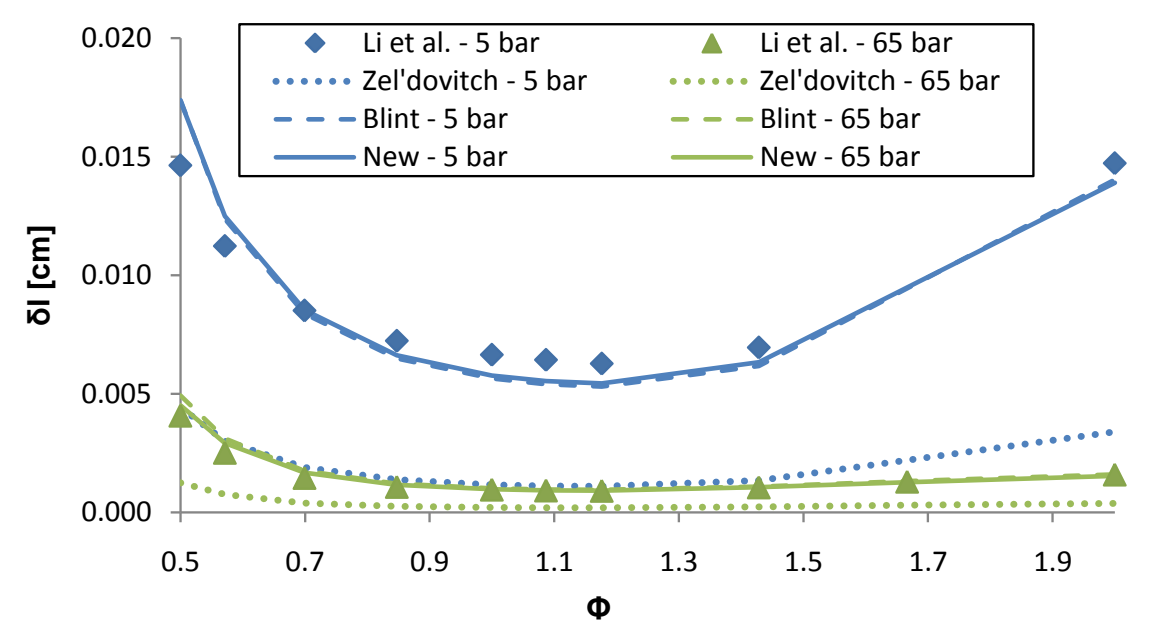

Figure 7: Laminar flame thickness variations with diluent ratio $f$ at unburned mixture temperatures $(p=15$ bar, $\phi=1)$ 